\title{
SELECTED PROBLEMS REGARDING CONSTRUCTION OF LIGHTWEIGHT MOTORCYCLE SWINGARM
}

\author{
WOJCIECH NOSKO', MIROSŁAW W. MRZYGLÓD ${ }^{2}$ \\ ${ }^{1}$ Opole University of Technology \\ Mikołajczyka 5, 45-271 Opole, Poland \\ wojciechnosko@gmail.com \\ ${ }^{2}$ Opole University of Technology \\ Mikołajczyka 5, 45-271 Opole, Poland \\ m.mrzyglod@po.edu.pl
}

Key words: Composite materials, CFRP, FEM, Structural analysis, Racing motorcycle, Swingarm,

\begin{abstract}
Manufacturers of light motorcycles have always sought the use of more and more advanced materials. The application of carbon fiber in motorcycle parts design can bring high strength, stiffness, and low weight in a manner previously unavailable. This article contains selected problems regarding the construction of a swingarm made of carbon fiber reinforced plastics (CFRP). The swingarm was made specifically for Honda NSF 100. For the analysis, series of tests such as geometry, FEM, and structural analysis was chosen. The analysis concludes that the swingarm shape that was adopted from the original steel made part is not suitable for CFRP use. The analysis showed manufacturing errors, like the inconsistent thickness of laminate and poor quality of assembling. The full potential of the CFRP material was not used.
\end{abstract}

\section{INTRODUCTION}

The use of carbon fiber in motorcycle parts design can bring high strength, stiffness, and low weight in a manner previously unavailable [1]. Composite materials offer freedom in material properties modification with such ease that cannot be compared to any other material [2].

The current evaluation will concern a swingarm prototype made of carbon fiber reinforced plastics (CFRP) and will be based on series of tests to provide a wide analysis of examined prototype. The swingarm design was adopted from the original part produced by Honda HRC company. The swingarm is a part of Honda NSF 100, the smallest production racer motorcycle offered by Honda.

The swingarm (Fig. 1) fabrication starts with the lamination of carbon fiber fabrics preimpregnated with epoxy resin (prepreg) into molds. The next step is to wrap it into a vacuum bag and place it in an autoclave where computer-controlled pressure and temperature allow to achieve the best possible composite properties. When the process of curing is finished swing arm halves are glued together with aluminum inserts in the special jig (Fig. 2). Such a 
manufacturing process allows saving more than $1 \mathrm{~kg}$ of the original part with increased stiffness [3].

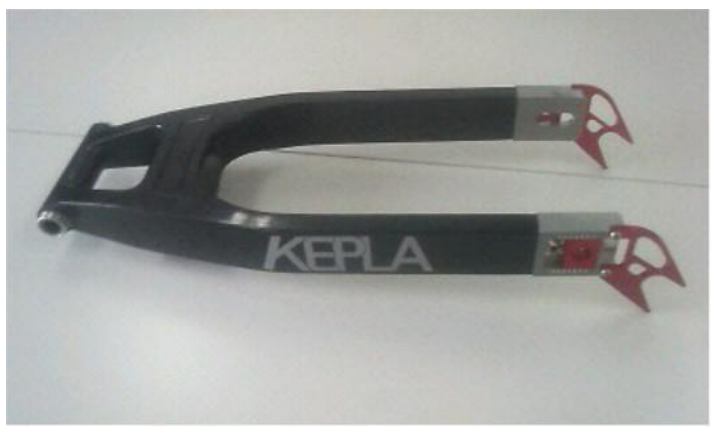

Figure 1: Tested CFRP swingarm

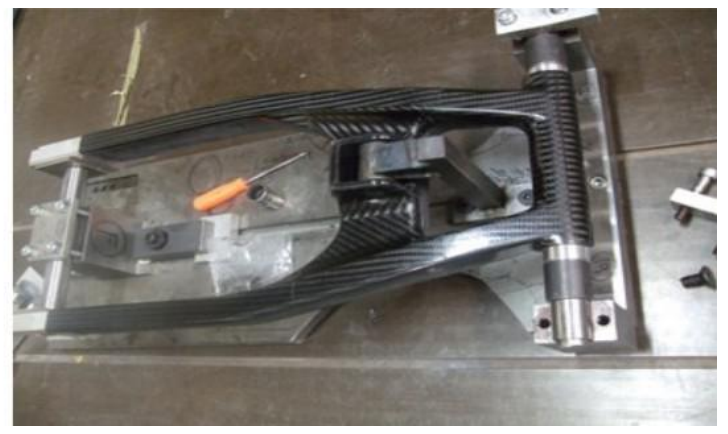

Figure 2: Assembly of swing arm components

\section{GEOMETRY ANALYSIS}

Measurements were made on the coordinate measuring machine Crysta-Plus 544 made by Mitutoyo company. The device equipped with indexed measuring head of repeal and rotary type MH20i with probe TP20 Measurements were performed at $20^{\circ} \pm 2^{\circ} \mathrm{C}$. Expanded uncertainty $\mathrm{U}= \pm(3.5+4.0 \mathrm{~L} / 1000)[\mu \mathrm{m}]$ where $\mathrm{L}$ is the measured length in millimeters.

These uncertainties are expanded type with a confidence level of $95 \%$ and a coverage factor $\mathrm{k}$
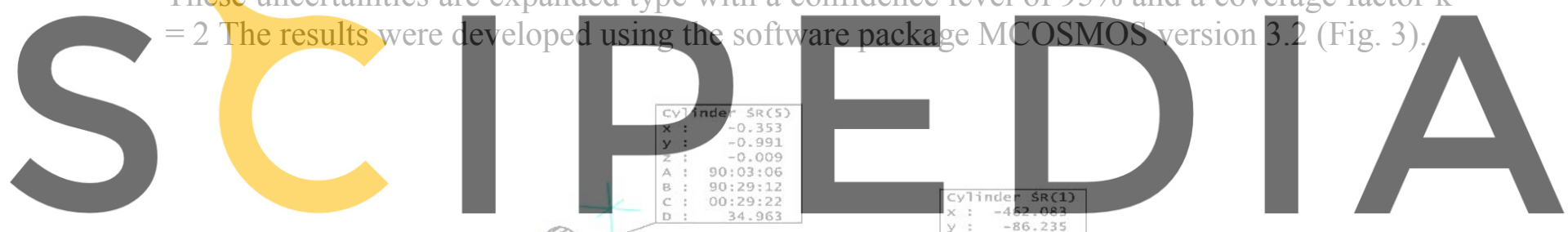

Register for free at https//4W.
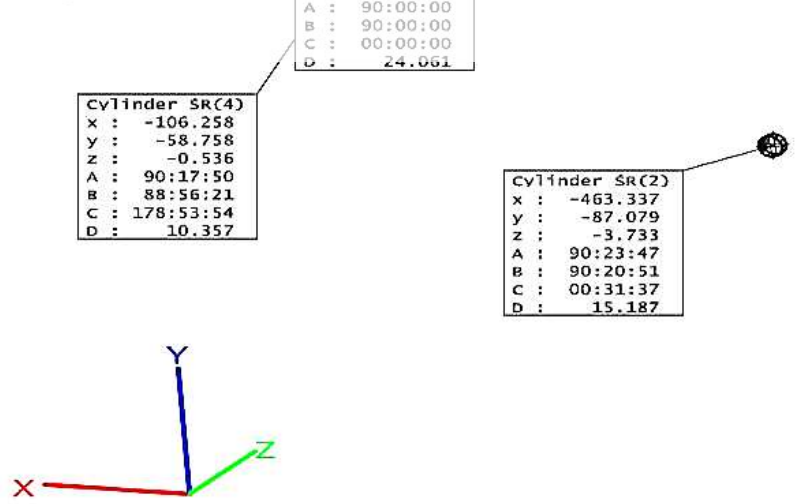

Figure 3: Datasheet of axle parallelism measurements

The swingarm attached to the testing bench was examined to establish its dimensional properties such as axis parallelism, rear inserts parallelism and perpendicularity, perpendicularity of swing arm surfaces, and its flatness. For this purpose, the beginning of the 
coordinate system (C.S.) was set up in two places, the first for perpendicularity measurements, on the very end of the rear left insert (wheel axle mounting). The second place was set up for axis parallelism measurements are placed on Cylinder (3).

\subsection{Results}

For the measurements purpose angle tolerance of flatness of $0.10^{\circ}$ was established. Further tests and their results were conducted without tolerance considered.

From the datasheet (Pic. 3) axis parallelism can be estimated. Cylinder ŚR (3) represents the axle of the swingarm pivot insert, and it was adopted as a measuring base. Two other axes of rear inserts (wheel axle mountings) are represented by Cylinder ŚR (1), and Cylinder ŚR. (2). Cylinder ŚR (4) represents the suspension damper mounting axis. Cylinder ŚR (5) represents the swing arm CFRP pivot area surface. Each Cylinder has its axis coordinates: $\mathrm{x}, \mathrm{y}, \mathrm{z}$ as well as the axis. Angle inclination: A - angle in term of axis $\mathrm{x}, \mathrm{B}-$ angle in term of axis $\mathrm{y}, \mathrm{C}-$ angle in term of axis $\mathrm{z}$. Conducted measurements showed that the axle of the swingarm pivot (Cylinder ŚR (3)) was not parallel to surrounded CFRP (Cylinder ŚR (5)) in which it was bonded. In $\mathrm{x}$ dimension is $0,353 \mathrm{~mm}$ and in y it is $0.991 \mathrm{~mm}$ different. The angle of the axle location according to the base was also warped. The axle of suspension damper mounting (Cylinder SR (4)) was not parallel as well as angle measurements state. Axle of Cylinder ŚR (2) was not parallel to Cylinder ŚR (3) axis. Axle of Cylinder ŚR (1) was not parallel to Cylinder ŚR (3) axis.
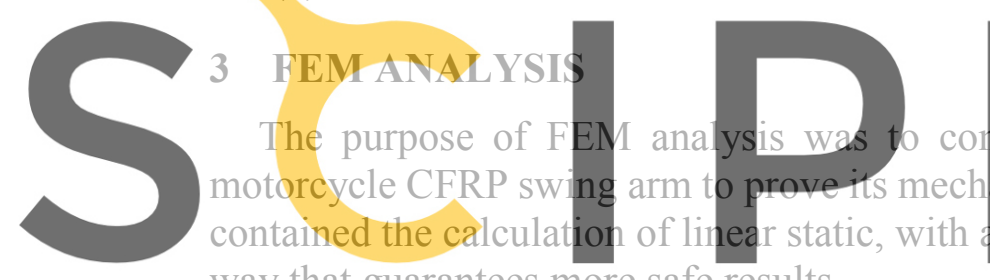

way that guarantees more safe results.
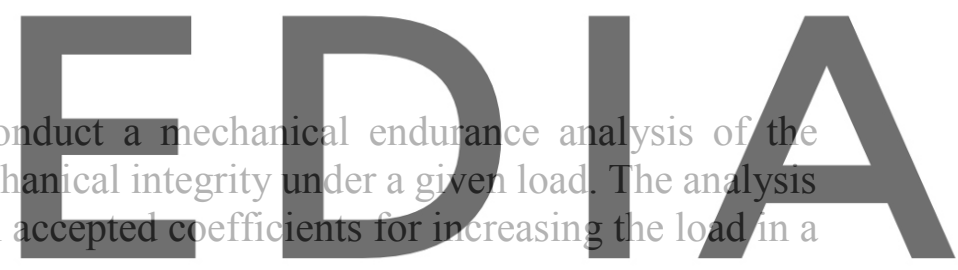

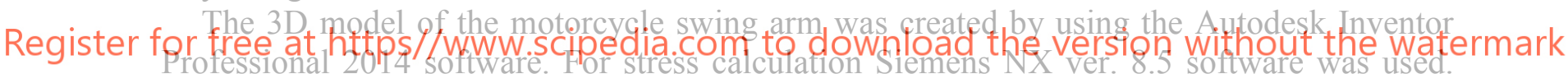

Pre/post-processing was made in the NX CAE module. Used Solver is NX Nastran ver. 8.5. 101 Analysis was used. To properly orientate fibers, analysis for isotropic material was made, then the direction of stress main tensors of I-st and 3-rd type was a check. Along with the direction of the biggest stress laminate fibers was apply. Analysis of the loaded model was conducted on its layers made of orthotropic material. Due to the simple geometry of the model (walls with the single curve) zone base model was applied. For creating the mesh Quad 4 elements were used for composite laminates and Tetra 10 for aluminum inserts. The joint between laminate and insert was modeled as a rigid glued joint. After conducting analysis and obtaining results maximum stress in glue was checked.

To verify swing arm strength, Tsai-wu and maximum stress hypothesis were used. To check if it does not exceed of limit maximum rigidity of the swing arm in critical points such as wheel axis, swing arm axis, and suspension strut mountings, was examined. Also, laminate was tested for delamination between laminate layers based on the difference between stress in each layer (shearing the resin). For safely permissible, 0.3 rates of destruction were applied.

The main part of examined detail is made of carbon fiber and epoxy resin prepreg. Laminate is built from eight layers in according order: 
1. 3 layers of TR3523 381 GMX twill $2 \times 2$ of $0.2 \mathrm{~mm}$ thickness each,

2. 2 layers of TRK510 $321 \mathrm{GMP}$ twill $2 \times 2$ of $0.57 \mathrm{~mm}$ thickness each,

3. 3 layers of TR3523 381 GMX twill $2 \times 2$ of $0.2 \mathrm{~mm}$ thickness each.

For aluminum inserts, alloy 6061 was applied. Mechanical properties of fibers, fabrics, and resin supplied by the producer were used to calculate general properties of laminates based on the „mixing rule.” $\mathrm{E}_{\mathrm{c}}$ (Young module of composites) $=\mathrm{E}_{\mathrm{r}}$ (Young module of resin) $\mathrm{x} \mathrm{V}_{\mathrm{r}}$ (resin volume $)+E_{f}$ (Young module of fiber) $x V_{f}$ (volume of fiber). Results from the „mixing rule” was then checked by tensile test in $0^{\circ}$ and $45^{\circ}$ on samples, cut directly from the swingarm. For bonding simulation properties of $3 \mathrm{M}$ Hysol structural glue was applied.

To dismiss the negative influence of boundary conditions on calculations results, the force of bearing type was applied on bonded aluminum inserts. Swingarm pivot was restrained by locking all degrees of freedom without rotation. Except for displacement in „,x, direction suspension strut mounting pivot have all degrees of freedom, due to simulating extreme situation when the damper is out of limit. For analysis (except for the first case of load) wheel axis was created to simulate the stiffness of wheel assembly.

\section{Dunning analysis five cases of swingarm load were examined:}

1. The suspension damper was connected directly to the swingarm mounting, and load $(2000 \mathrm{~N})$ was applied on the surface where the rear wheel axial touch insert,

2. Horizontal load $(800 \mathrm{~N})$ from the right side to the left was applied to proper surfaces on the swing arm inserts,
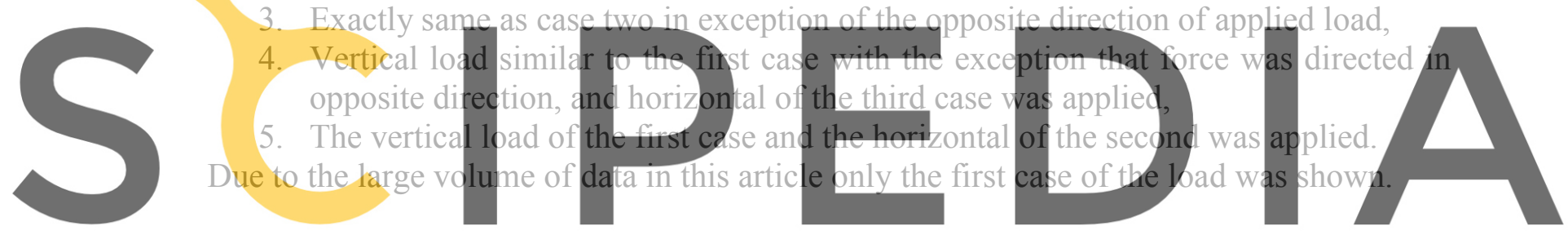

\subsection{Results}

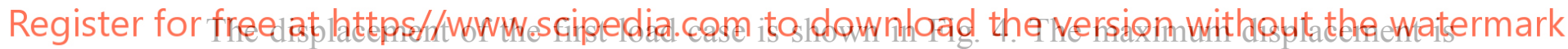

$6.012 \mathrm{~mm}$, distinct color of both beams' ends indicates that the displacement is not equal. For the left beam, it was about $0.5 \mathrm{~mm}$ smaller than for the right one.

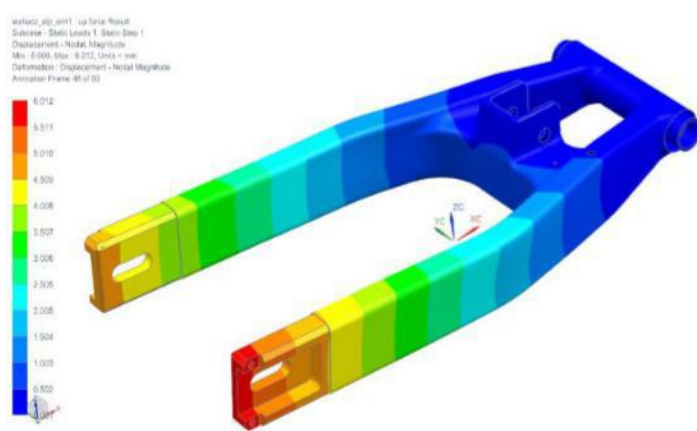

Figure 4: Displacement analysis: first load case

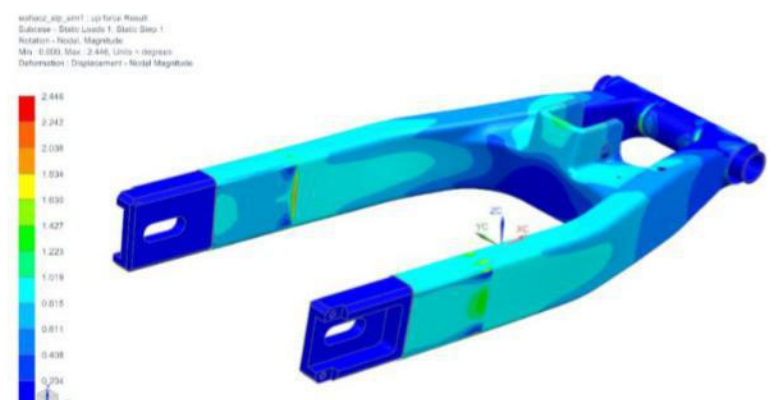

Figure 5: Displacement analysis: inserts rotation

Inserts rotation analysis shows maximum angle rotation of 2.446 degrees on the end of the 
installed inserts (see Fig. 5). This may be the place of the stress concentration due to much higher stiffens of insert compared to CFRP laminate.

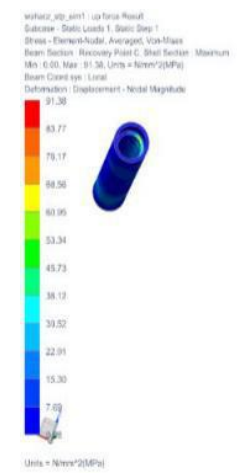

Figure 6: Von Mises stress: inserts

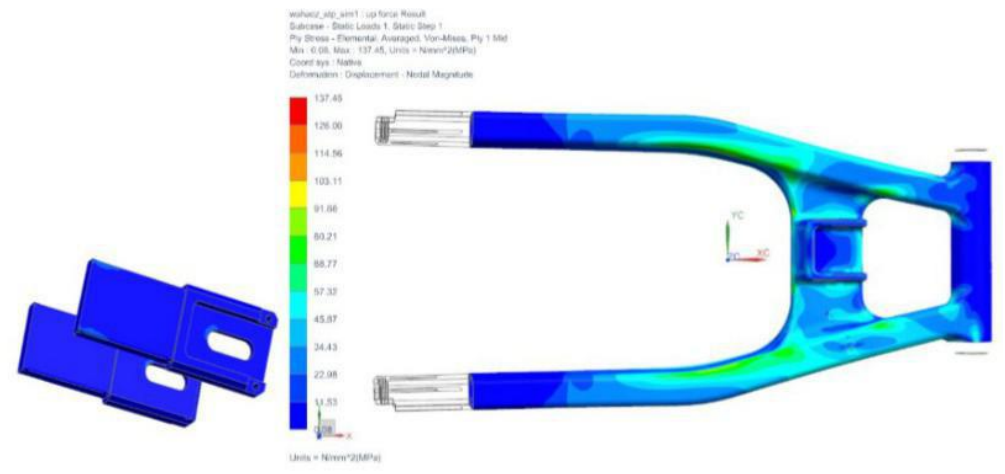

Figure 7: Von Mises stress: top view of the laminate

The maximum value of 91.38 MPa occurs in the swingarm axis mounting insert (see Fig. 6). On the very edge of needle bearing locking edge. This high value is a calculating error and will not be discussed in the further comment. The maximum stress of wheel axis mounting is much lower and is $10.5 \mathrm{MPa}$. Such small stress indicates that inserts themselves are oversized and their shape should be optimized for better strength to weight ratio.

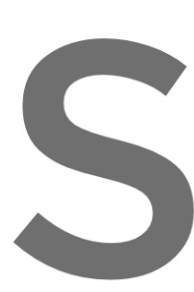

Stress analysis of

appears on the downside Fig. 8-9).

Register for free at https//www.scipedia.com to
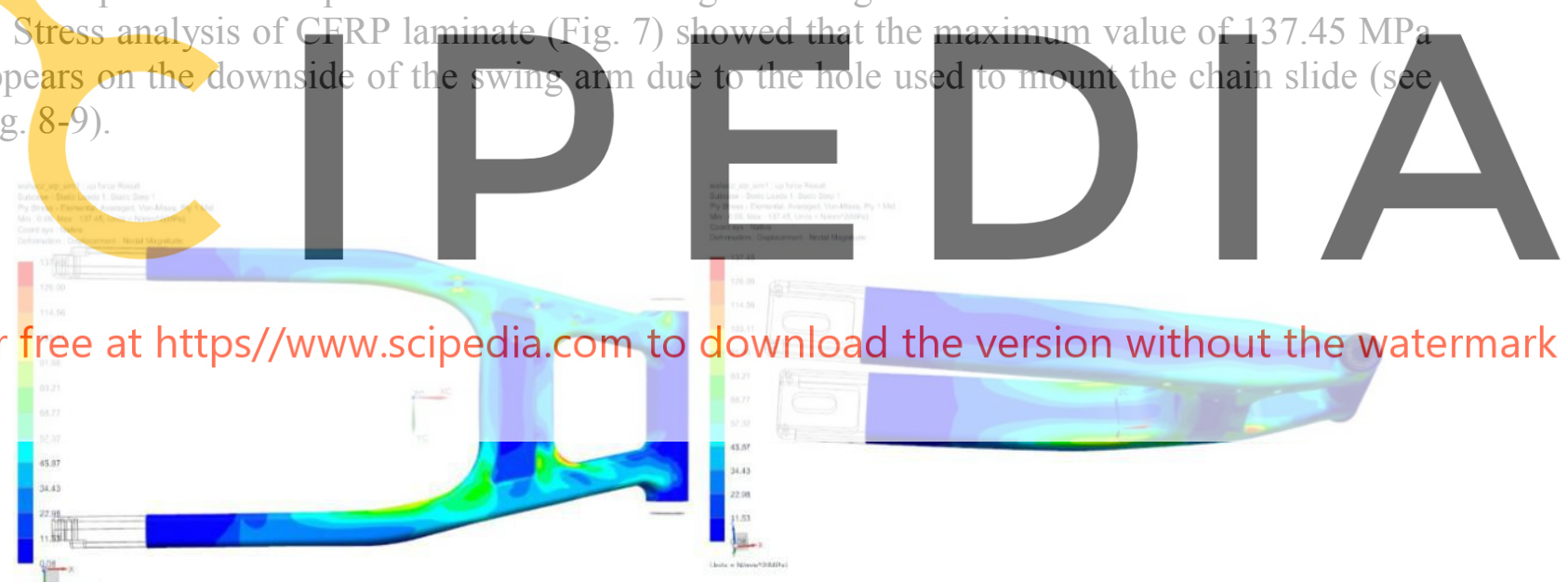

Figure 8: Von Mises stress: bottom view

Figure 9: Von Mises stress: right side view

As it is shown, the higher stress values appear on the top and bottom wall of the swing arm beam. This means that the hole in its current position works as a notch and should be considered as a design flaw. Chain slide instead of bolted should be glued to swing arm surface.

Stress in plies is presented in Fig. 10-13. The changes and transition of stress in plies can be observed. Starting from ply 1 where the highest stress occurs in the mounting hole, finishing on ply 8 where the high value of stress $(698 \mathrm{MPa})$ appears in the first hole from the left side of the swingarm. An increase of stress can also be seen in the area of suspension damper mounting (Fig. 14-17). Though stress around the damper mounting area is within the acceptable limit, it shows that there is a possibility for design optimization. 


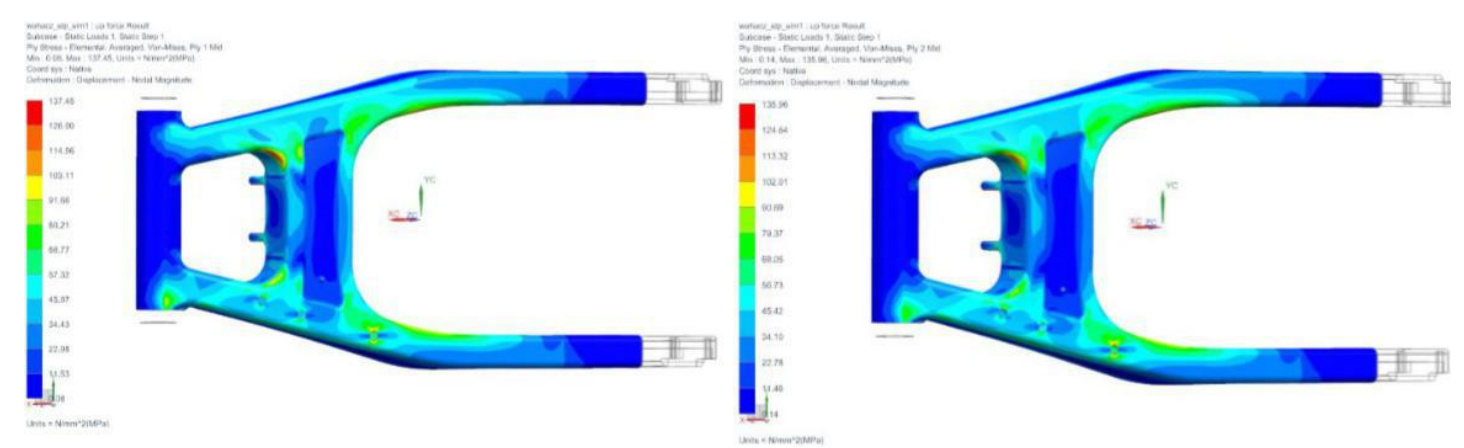

Figure 10: Von Mises stress in ply 1

Figure 11: Von Mises stress in ply 2
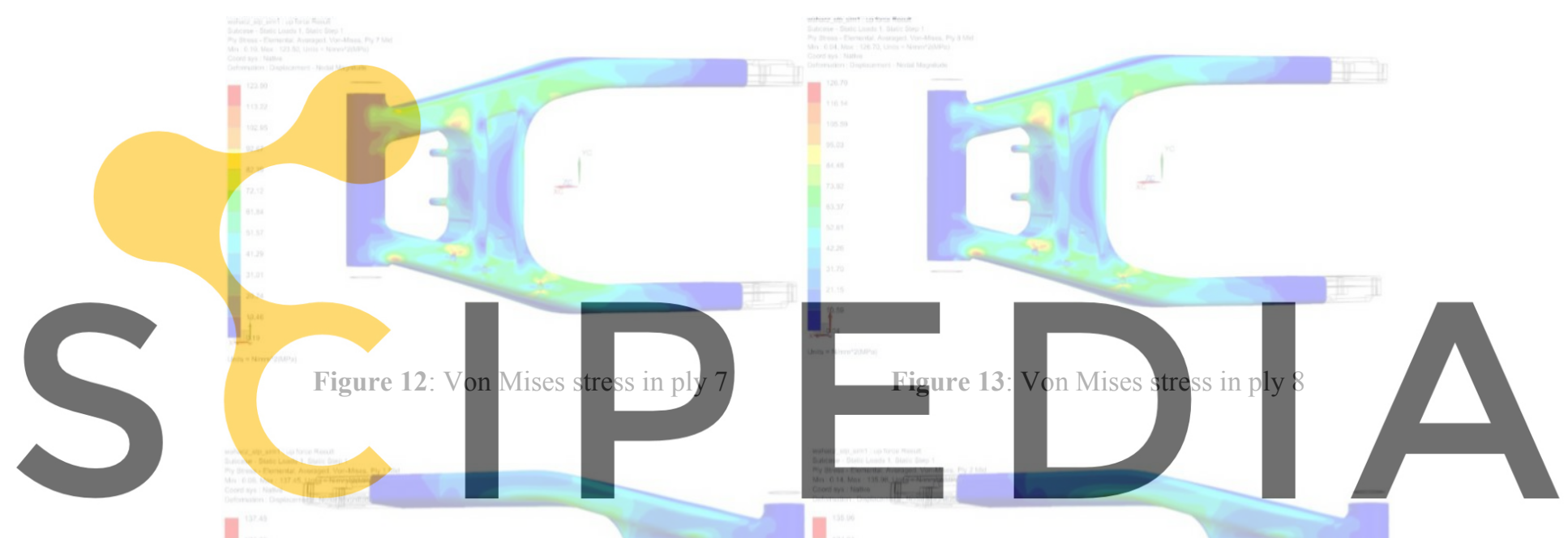

Register for free at https//www.scipedia.com to download the version without the watermark

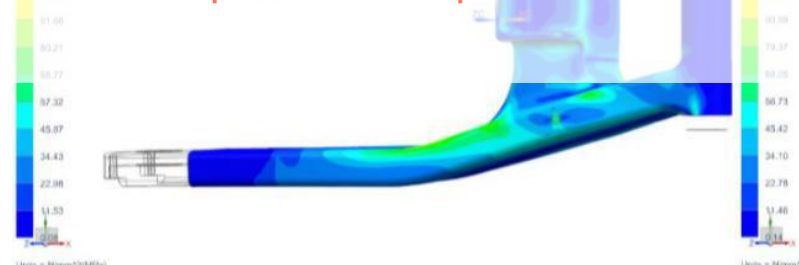

Figure 14: Von Mises stress in ply 1

Figure 15: Von Mises stress in ply 2 


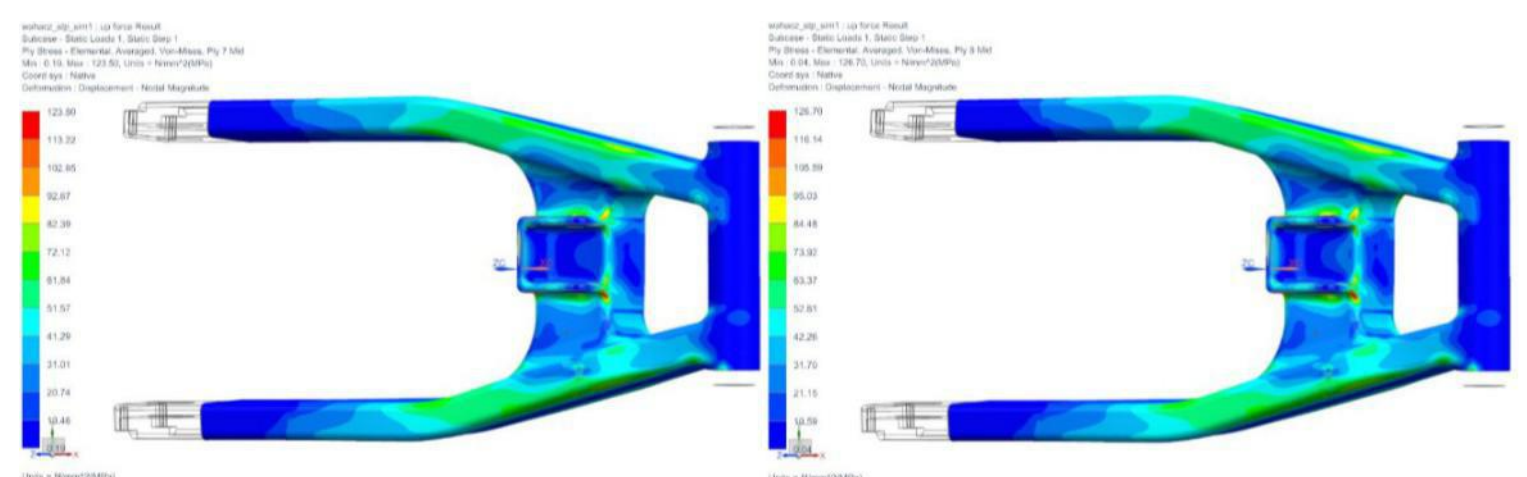

Figure 16: Von Mises stress in ply 7

Figure 17: Von Mises stress in ply 8

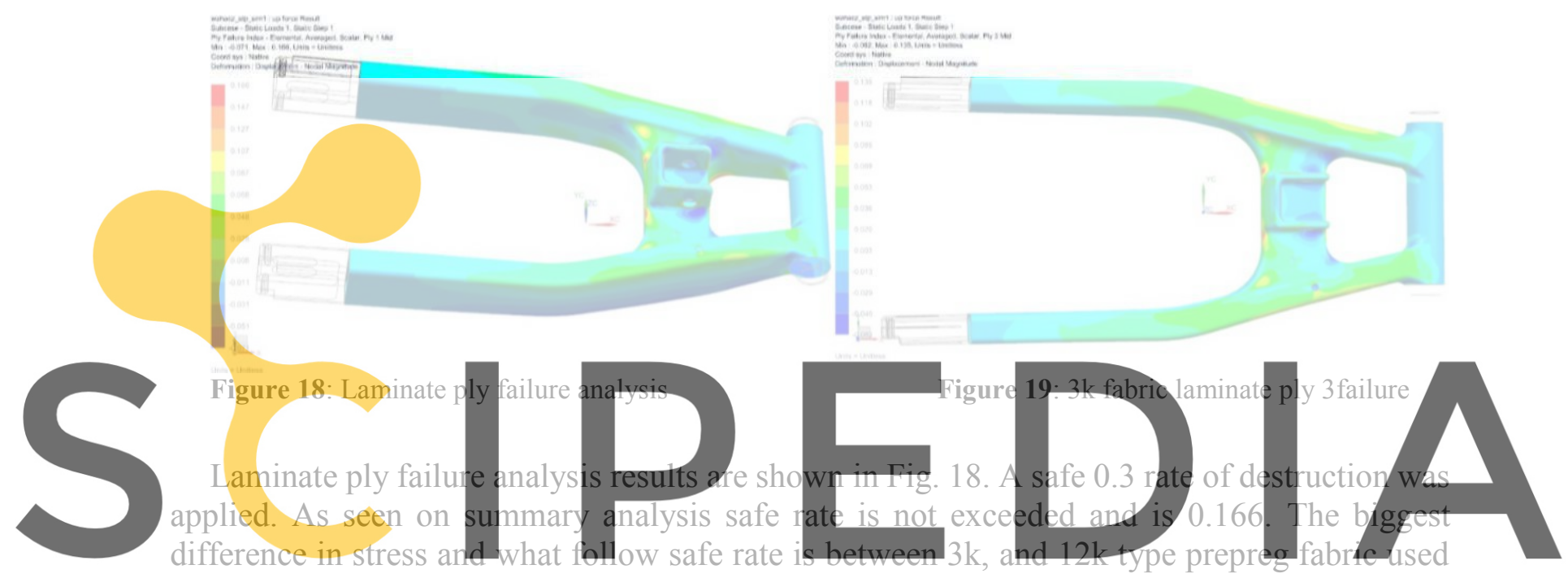

to build laminate thickness (Fig. 19-21) This behavior proves proper calculation results as the

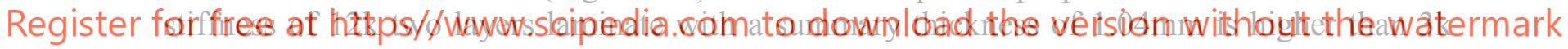
three layers of summary thickness of $0.6 \mathrm{~mm}$. Therefore, such disparity may be the reason for delamination on the border between ply numbers 3 and 4,5 and 6 . By laminating stiffer fabric on the top (12k over $3 \mathrm{k})$ where stress which came from the load is highest such difference in stress distribution across laminate composition could be avoided.

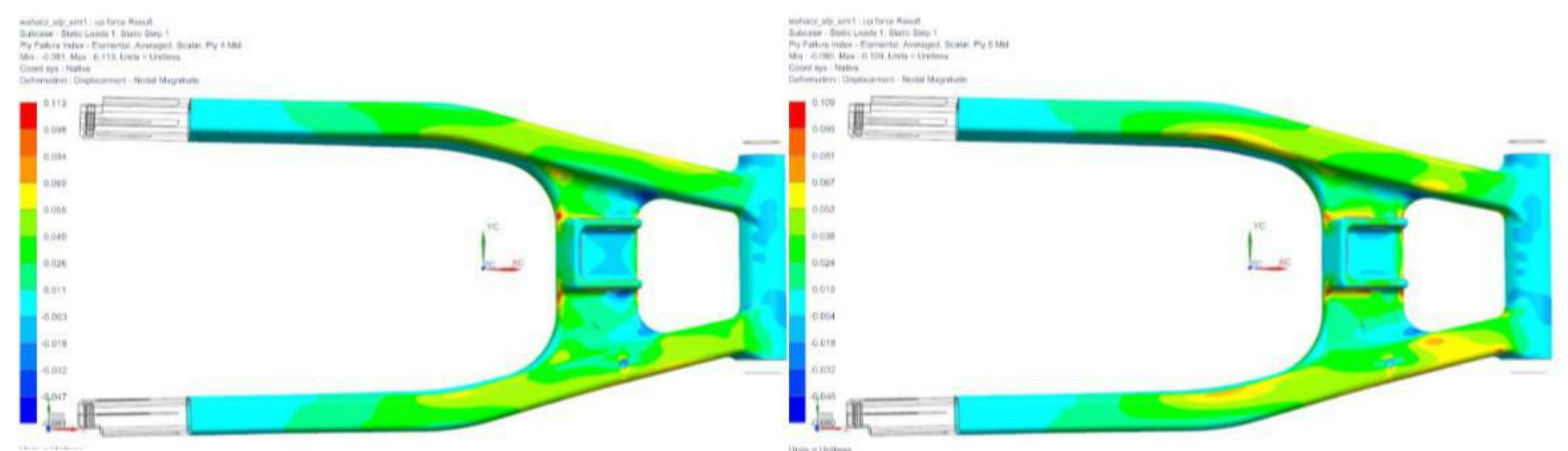

Figure 20: $3 \mathrm{k}$ fabric laminate ply 4 failure rate

Figure 21: 3k fabric laminate ply 5 failure rate 


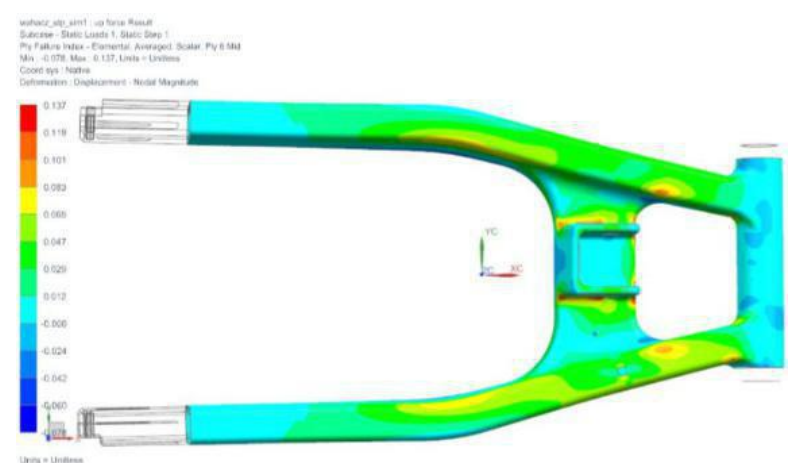

Figure 22: 3k fabric laminate

\section{STRUCTURAL ANALYSIS}

Structural analysis of swingarm was conducted to determine the quality of laminate. The internal structure analysis was conducted with the use of tomography Metrotom 1500 of Carl Zeiss company. At first, the 3D model was created by use of tomography, and with-it internal structure was revealed. In Fig. 23 and 24, different views of the same 3D model are shown.

The analysis of the x-ray image is presented in Fig. 25 and 26. As seen in the figure, voids occurred in swing arm components on the right side of the beam, and around the swingarm
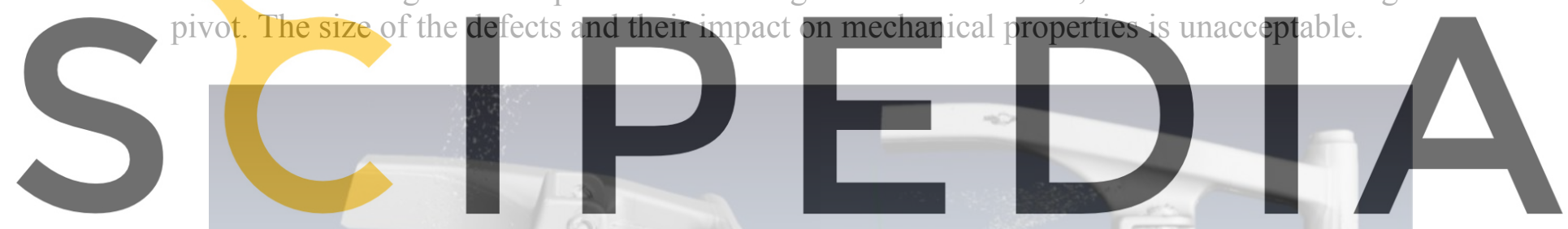

Register for free at https//www.scipedia.com to download the version without the watermark

Figure 23: 3D model: view of right side

Figure 24: 3D model: view of the top side

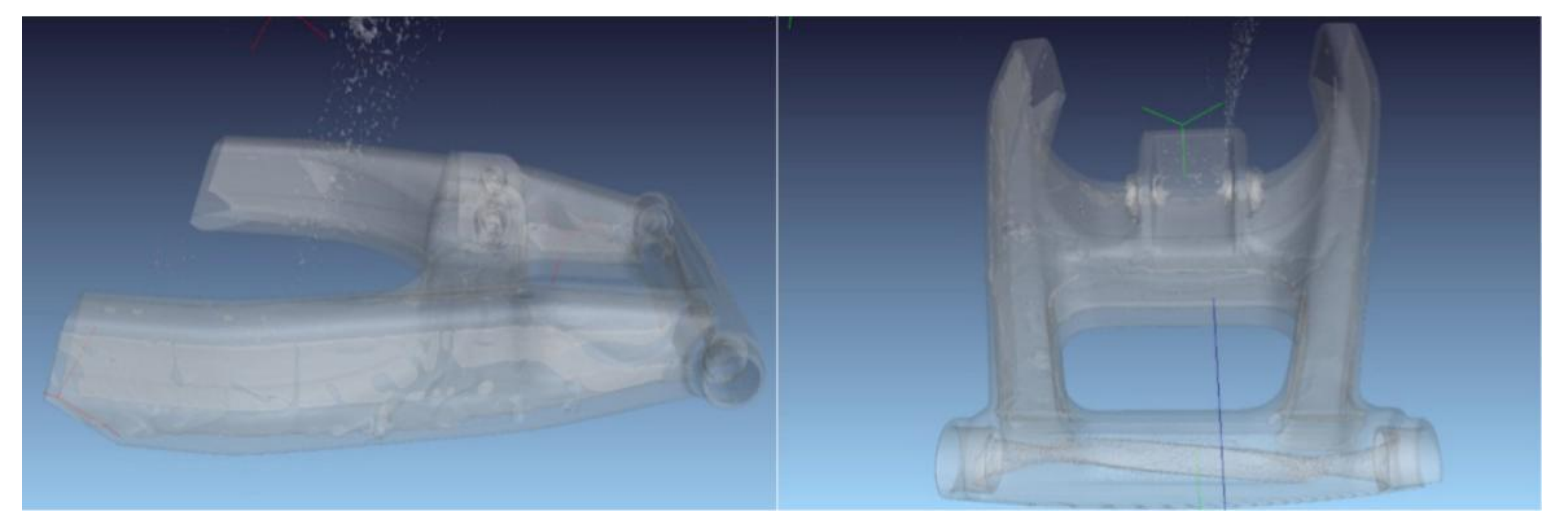

Figure 25: X-ray analysis: view of right side

Figure 26: X-ray analysis: view of the front side 
In Fig. 27, the cross-sections of the LH swing arm beam are shown. Uneven thickness of laminate, voids, and glue residue was discovered. The following laminate arranged was used according to manufacturer datasheet: 3 layers of TR3523 381 GMX twill 2x2 of $0.2 \mathrm{~mm}$ thickness each, 2 layers of TRK510 321GMP twill $2 \times 2$ of $0.57 \mathrm{~mm}$ thickness each, 3 layers of TR3523 381 GMX twill $2 \times 2$ of $0.2 \mathrm{~mm}$ thickness each. The total thickness sum is $2.34 \mathrm{~mm}$. As figures showed, the thickness differs depend not only on location in a single cross-section but also on the length of the beam (see Fig. 27).

The RH beam cross-section is shown also in Fig. 28. Even more intense defects are discovered in RH beam, not only voids are presented but also unglued overlap surfaces.

A cross-section of the member of the swing arm is shown in Fig. 29. Large glued joint defects are visible with voids and uneven laminate thickness. A cross-section analysis of the suspension damper mounting area is shown in Fig. 30. The voids of the high content of the resin and prepreg fabric wrinkles can be observed.

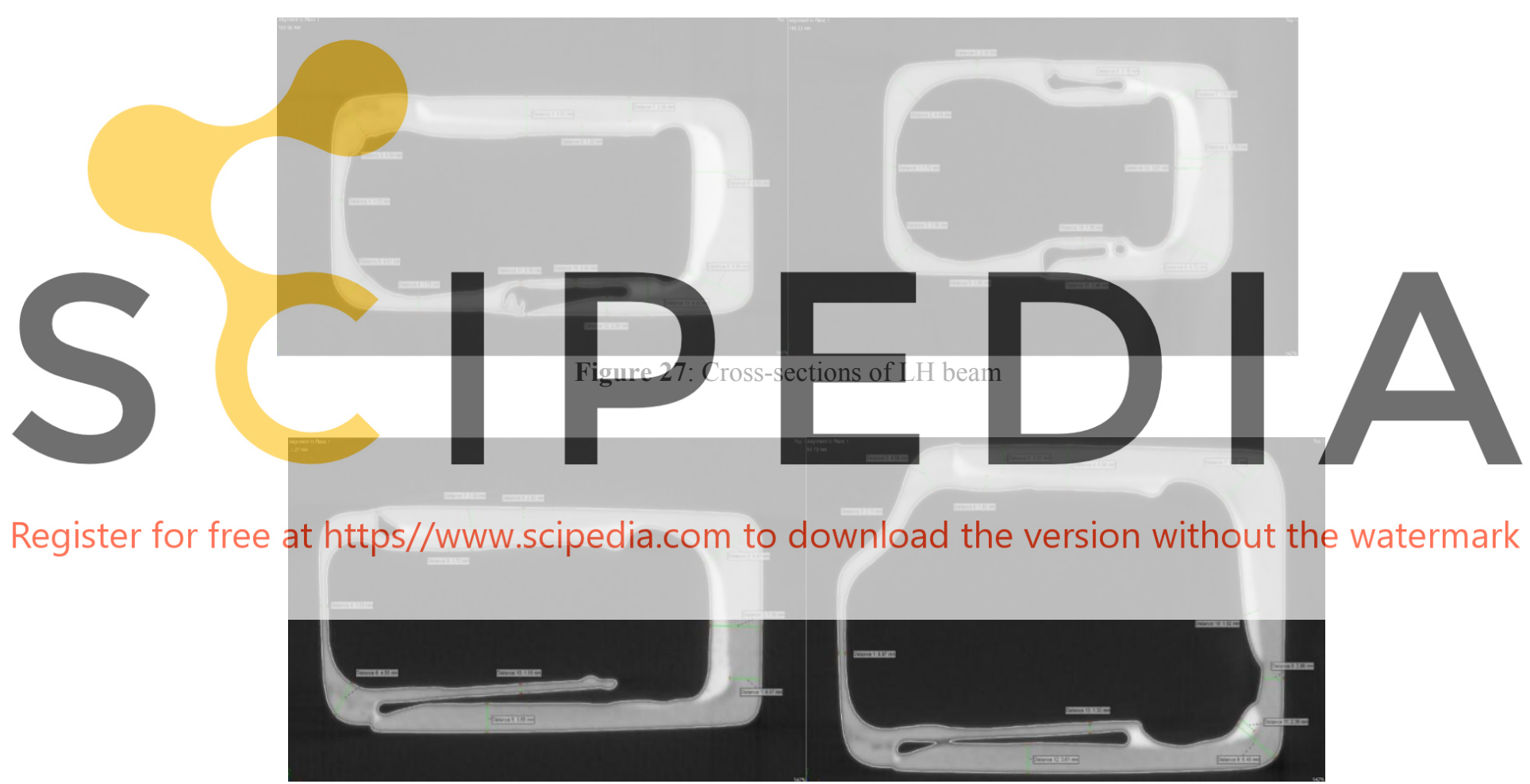

Figure 28: Cross-sections of LH beam 

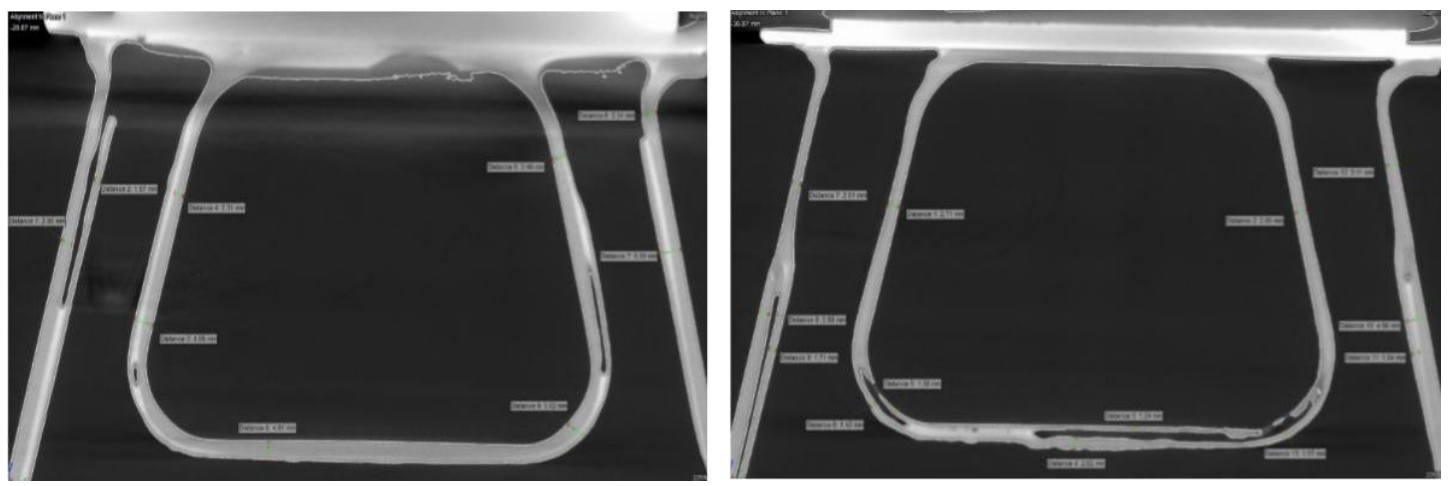

Figure 29: Cross-sections of the swingarm

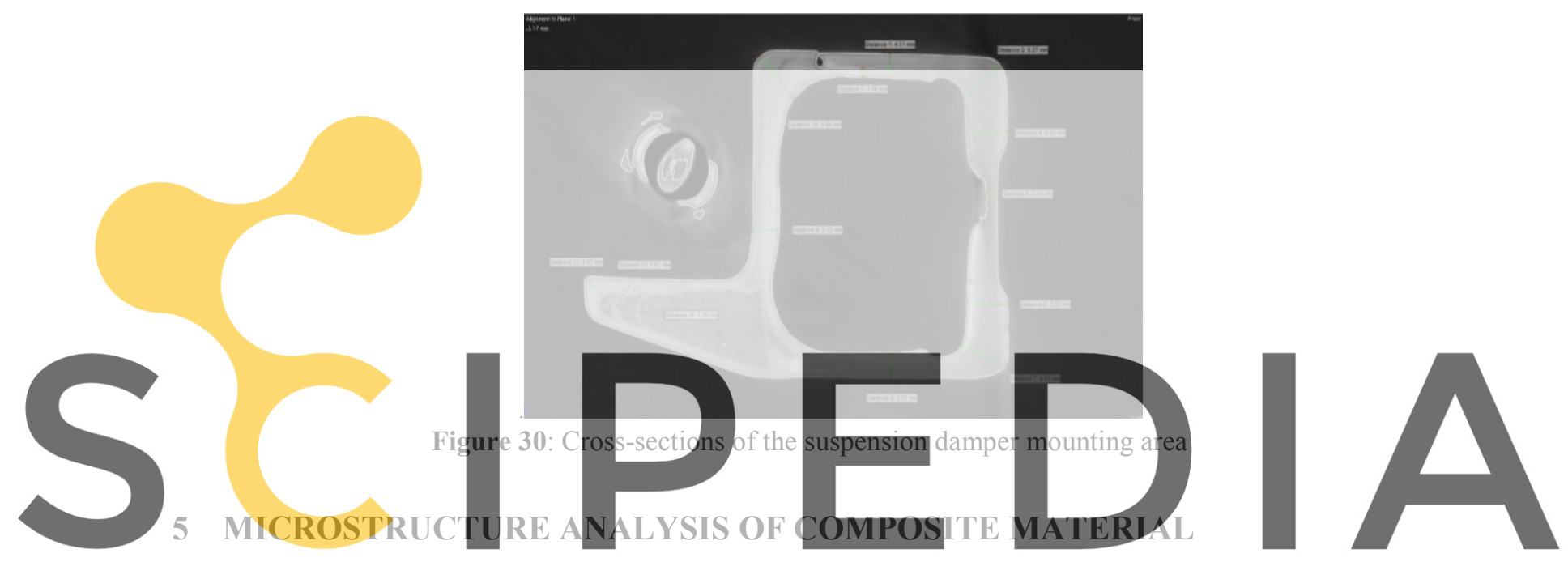

Composite material test samples were cut from the place of the suspected crack (see Fig.

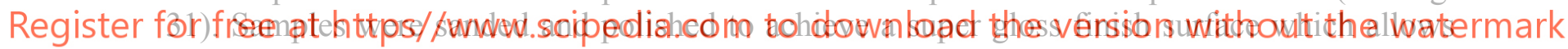
making high-resolution pictures of the structure. The aluminum alloy used for the insert was etched with the use of $10 \%$ hydrofluoric acid. Pictures were made on Cannon Eclipse MA200 inverted metallurgical microscope with x100 magnification. Pictures of a cross-section of the laminate are shown in Fig. 32-33.

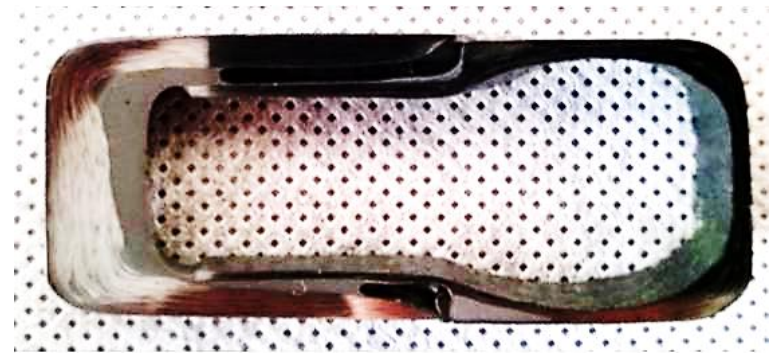

Figure 31: Composite material test sample of swing arm left beam cross-sections

In Fig. 31 internal defects are visible. Not only a lack of bond between two swing arm parts but also the difference in laminate thickness can be noticed. The lower part which 
embraces overlap is thicker on the bottom and thinner on the sides. The upper part is made with the use of fewer layers of fabric which causes a thinner cross-section. A big residue of the bond was found on the bottom of the swingarm beam. To finishing the assembly of the product, two types of bond are used, first, to glue swingarm parts together, the second one to cover the gap which remains after the joining process. The microstructure view of the lower part of the swingarm (element embracing overlap) is presented in Fig. 32.

In Fig. 32, the CFRP laminate with a cross-section of fabric fibers is shown. Large distances between fibers adversely affect mechanical properties. Higher resin to fiber ratio is the effect of chaotic laminate composition and insufficient vacuum bag pressure on laminate. Sidewalls of the same element where laminate scheduled are orderly placed, we can see the more tight arrangement of fabric and lower resin to fiber proportion (see Fig. 33). Furthermore, no internal defects of laminate were detected. The microstructure of glued joint is presented in Fig. 34. No cracks were detected on the aluminum to CFRP bond border. Some defects (pores) were noticed in the glued structure which has a negative impact on the mechanical properties of the joint itself.

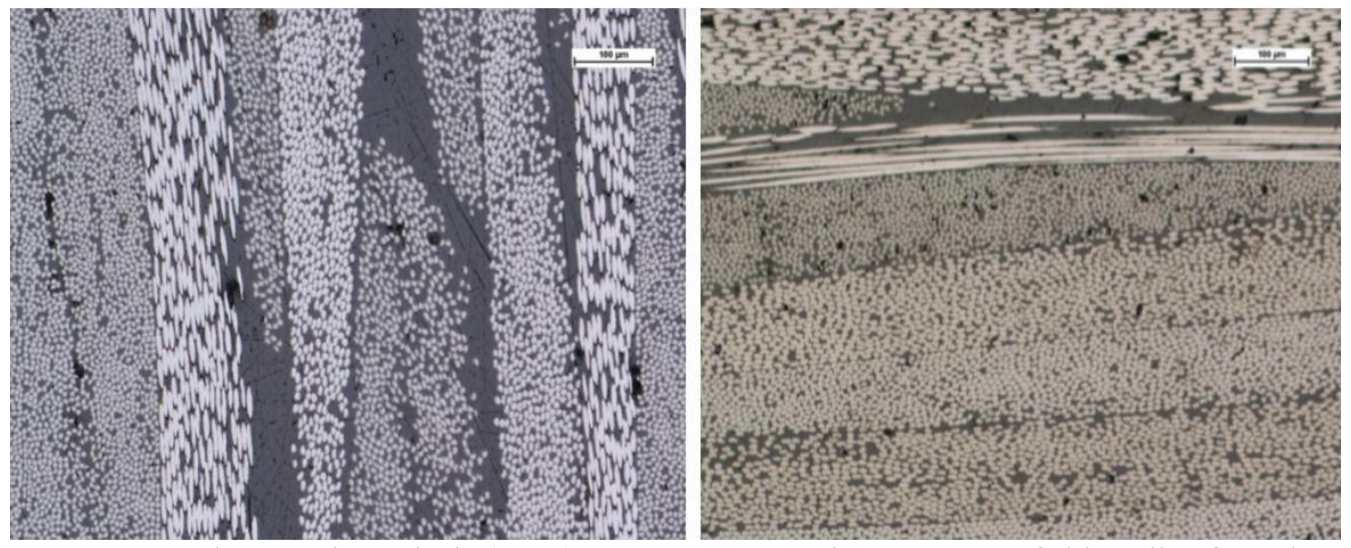

Figure 32: Microscopic analysis (x100)
Figure 33: Microstructure of sidewalls of overlap

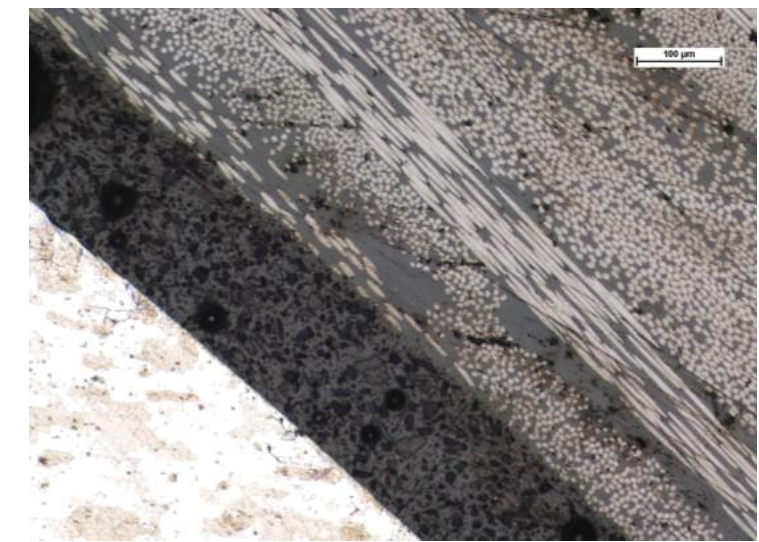

Figure 34: Microstructure of bonded joints between CFRP laminate and aluminum insert 


\section{CONCLUSIONS}

In the article, selected problems regarding the construction of the lightweight motorcycle swingarm were presented. The extensive analysis of swingarm structure consisted of tomography analysis of geometry, FEM analysis of endurance, and microstructure analysis of composite material.

The swingarm was manufactured specifically for Honda NSF 100 using CFRN composite material. The analysis reviled that the swingarm shape adapted from the original steel part was not suitable for CFRP use. Moreover, the aluminum inserts used to hold bearings or wheel axis were oversized and had stiffness much higher than laminate what caused the formation of stress concentration. That also increased the overall weight of the product making the use of CFRP material questionable. Despite the good overall laminate quality, the analysis showed no consistent thickness. Furthermore, the two parts of the complete swingarm were poorly glued together. The design of the assembly jig does not guarantee the good geometry of the final product. Even though the motorcycle swingarm was produced it cannot be considered technologically correct.

Further investigation of authors will be aimed at developing a methodology for designing the shape of the swingarm dedicated to the composite material.

\section{REFERENCES}

[1] Savage, G.: Formula 1 Composites Engineering, Eng. Fail. Anal. (2010) 17:92-115.

[2] Legrand, M., Ngoc, Q.A.P.: A study of feasibility of a monoblock racing motorcycle rim. Compos. Sci. Technol. (2001) 61:453-458

[3] O'Dea N.: Motorcycle swingarm redesigned in carbon composite, Reinforced Plastics (2011) 55(6)November-December:38-41. 